Proc. Indian Acad. Sci. (Chem. Sci.), Vol. 89, Number 2, April 1980, pp. 163-173.

(C) Printed in India.

\title{
Vibrational and electronic absorption spectra of 4-chloro 2-methyl, 4-chloro 3-methyl and 6-chloro 3-methyl phenols
}

\author{
R B SINGH* and D K RAI \\ Laser and Spectroscopy Laboratory, Department of Physics, Banaras Hindu \\ University, Varanasi 221005 , India \\ * On leave from S.K.R. College, Barbigha, Monghyr, India
}

MS received 21 July 1979

\begin{abstract}
The infrared spectra of 4-Cl 2-Me, 4-Cl 3-Me and 6-Cl 3-Me phenols have been recorded. The vibrational spectrum has been analysed assuming that the molecules belong to $C_{s}$ point group and a tentative assignment of the observed frequencies to various modes of vibration has been proposed. The near ultraviolet absorption spectrum of these compounds has also been recorded. Assuming the transition to be electronically allowed the strongest band on the longer wavelength side has been assigned as the $(0,0)$ band in each case. The spectrum has been analysed in terms of several excited state frequencies which have been correlated with the ground state frequencies observed in the infrared spectrum.
\end{abstract}

Keywords. Infrared; ultraviolet absorption ; electronic absorption; vibrational analysis.

\section{Introduction}

Spectroscopic studies of chloro and methyl phenols have been reported in the literature (Green and Harrison 1971; Rao 1962; Cave and Thompson 1950; Green 1962). However no study of the spectroscopic properties of di-substituted phenol containing both chlorine and methyl substituents has been reported so far. This prompted us to undertake the spectroscopic study of several chloro-methyl phenols. The results of our study of the infrared and the near ultraviolet absorption spectra of 4-Cl 2-Me, 4- $\mathrm{Cl} 3-\mathrm{Me}$ and 6-Cl 3-Me phenols are presented here.

\section{Experimental}

Pure samples of the compounds under investigation were obtained from Dr. Theodor Schuchardt, Munchen. All the three compounds are solid at room temperature $\left(30-40^{\circ} \mathrm{C}\right)$.

The infrared spectra were recorded on Perkin-Elmer infrared spectrophotometer (Model 621) in the range $\left(200-4000 \mathrm{~cm}^{-1}\right)$ using Nujol Mull solution.

P. (A)-8 
The ultraviolet absorption spectra were recorded on Hilger medium quartz spectrograph. The compounds were kept in an absorption cell of length $125 \mathrm{~cm}$ and diameter $2.5 \mathrm{~cm}$. The temperature of the cell could be varied and it was found that the absorption spectra were best developed when the temperature was $40^{\circ} \mathrm{C}$. A $150 \mathrm{~W}$ Beckman hydrogen lamp was used as a source of continuum and exposure time of $\mathbf{4 0} \mathrm{min}$ was found sufficient to record the spectra on IIford special rapid plates with sufficient intensity. The spectra were measured from positive prints using a comparator with a least count of $10^{-4} \mathrm{~mm}$. The infrared absorption spectra of 4-Cl 2-Me, 4-Cl 3-Me and 6-Cl 3-Me phenols are shown in figures la, $1 \mathrm{~b}$ and $1 c$.

\section{Resalts and discussion}

\subsection{Infrared spectrum}

It is customary to treat each multiatomic substituent, e.g., $\mathrm{CH}_{\mathbf{3}}$ or $\mathrm{OH}$ as a point mass so that all substituted benzenes have only 30 normal modes of vibration. Since the molecules under consideration are assumed to belong to $C$, point group, 21 of these vibrations would be $\left(a^{\prime}\right)$ planar and $9\left(a^{\prime \prime}\right)$ non-planar. In addition to these 30 vibrations there would be 12 additional vibrations due to the internal

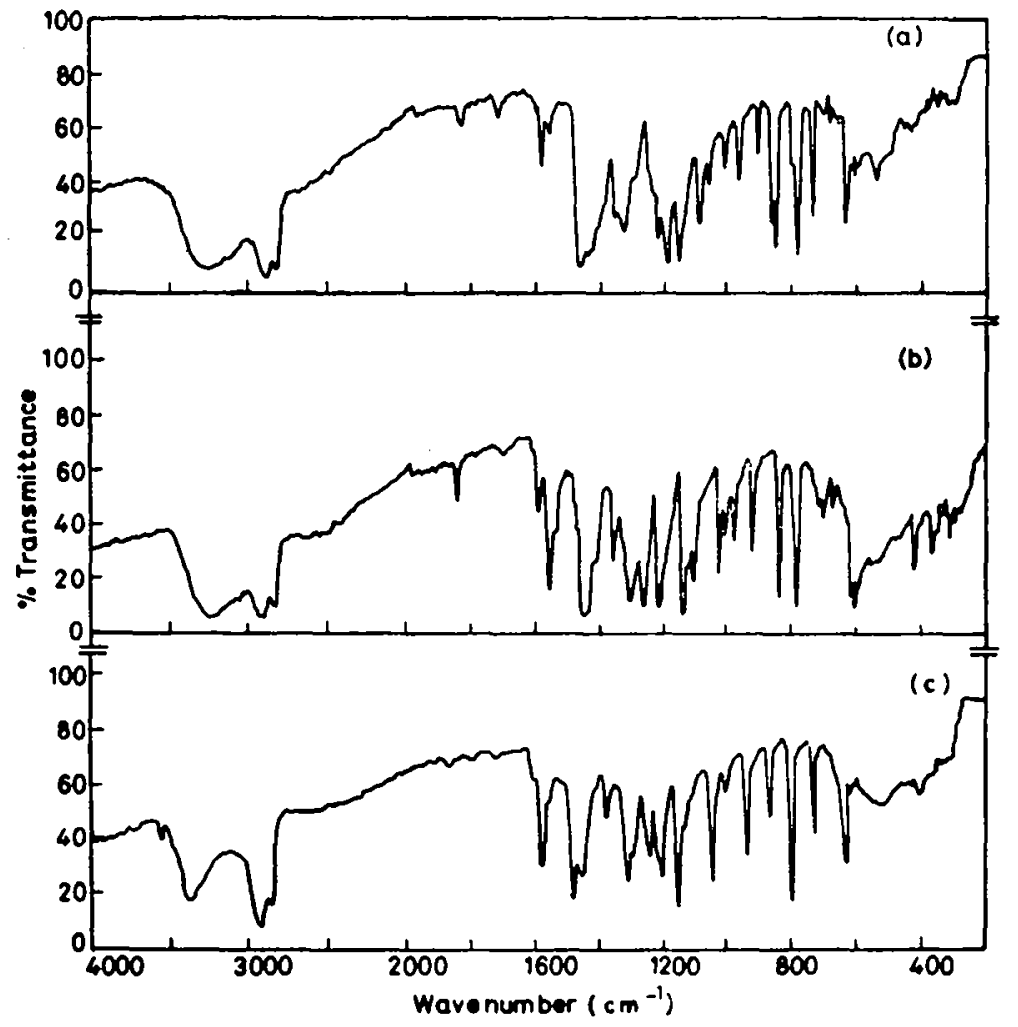

Figure 1. Infrared absorption spectrum, a. 4-chloro 2-methyl phenol; b. 4-chloro 3-methyl phenol; c. 6-chloro 3-methyl phenol. 
motion in the substituents. For $C$, point group all the vibrations, i.e., whether they are of type $a^{\prime}$ or $a^{\prime \prime}$ are both infrared and Raman active.

Varsanyi (1969) developed a system of classifying a substituent as either "light " or " heavy" to systematise the assignments of observed frequencies in substituted benzenes to the various benzene modes. On the basis of this classification he suggested suitable ranges of frequencies to which the various benzene type modes should be assigned in the spectrum of substituted benzene. In making the assignments in the present work we have kept in mind these suggestions of Varsanyi (1969) and have also considered the assignments suggested by earlier workers in ortho and meta cresols (Rao 1962), para-chloro phenol (Green and Harrison 1971), 2,3-dichlorophenol (Sanyal and Pandey 1973) and chloro-methyl aniline (Sharma and Dwivedi 1976). The proposed assignments are given in table 1.

3.1a. Stretching vibrations $v(C-H)$ and $v(C-X)$. Out of six $\mathrm{C}-\mathrm{H}$ stretching modes appearing in benzene three are transformed into three $\mathrm{C}-\mathrm{X}$ stretching modes. In the present set of molecules these involve $\mathrm{C}-\mathrm{OH}, \mathrm{C}-\mathrm{CH}_{3}$ and $\mathrm{C}-\mathrm{Cl}$ stretching modes.

Bellamy (1964) and Rao (1963) have suggested that $\mathrm{C}-\mathrm{Cl}$ stretching vibration in substituted benzene appears in the frequency range $600-800 \mathrm{~cm}^{-1}$. It is also expected to appear very prominently in the infrared spectrum. In the present investigation one infrared band has been observed in the ahove frequency range with large intensity in all the three compounds and has been explained as being due to $\mathrm{C}-\mathrm{Cl}$ stretching mode.

C- $-\mathrm{CH}_{8}$ stretching vibration causes strong absorption in the range $1150-1200 \mathrm{~cm}^{-1}$ (Sharma and Dwivedi 1976). This stretching frequency has been assigned at $1195 \mathrm{~cm}^{-1}$ for 4-Cl 2-Me and at $1190 \mathrm{~cm}^{-1}$ for 6-Cl 3-Me phenol.

Numerous investigators (Sanyal and Pandey 1973; Mecke and Rassmy 1955; Bellamy and Davis 1948) assigned a band near $1250 \mathrm{~cm}^{-1}$ as due to $\mathrm{C}-\mathrm{OH}$ stretching vibration in substituted benzenes containing $\mathrm{OH}$ group. We have assigned the bands at 1250,1235 and $1250 \mathrm{~cm}^{-1}$ to this mode in 4-Cl 2-Me, 4-Cl 3-Me and 6-Cl 3-Me phenols respectively.

Three $v(\mathrm{C}-\mathrm{H})$ stretching vibrations are also expected in addition to three $v(\mathrm{C}-\mathrm{X})$ stretching vibrations already discussed above. These vibrations usually appear in the region $3000-3100 \mathrm{~cm}^{-1}$ and are easily assigned as shown in table 1 .

3.1b. Stretching vibrations $v(C-C)$ : Except for the totally symmetric ring breathing (mode 1) vibration all the remaining five $\mathrm{C}-\mathrm{C}$ stretching vibrations in benzene appear in the frequency range $1300-1600 \mathrm{~cm}^{-1}$ (Varsanyi 1969). Some of these vibrations are significantly affected in magnitude on substitution, while the others remain almost unchanged. The assignments of these modes to the various observed frequencies on the basis of similar assignments by other workers (Sanyal and Pandey 1973; Sharma and Dwivedi 1976) are as shown in table 1. The ring breathing vibration is also greatly affected. We have chosen the frequencies $1035 \mathrm{~cm}^{-1}, 1045 \mathrm{~cm}^{-1}$ and $1040 \mathrm{~cm}^{-1}$ involved in bands which appear with large intensity as the ring breathing frequency of 4-Cl 2-Me, 4-Cl 3-Me and 6-Cl 3-Me phenol respectively.

3.1c. Ring in-plane bending $\phi(C-C-C)$ vibrations. There are three (C-C-C) inplane bending vibrations in substituted benzenes. $\mathrm{Th}_{\boldsymbol{\rho}}$ assignments of $\mathrm{t}_{\text {hese }}$ 
Table 1. Infrared absorption of $4-\mathrm{Cl} 2-\mathrm{Me}, 4-\mathrm{Cl} 3-\mathrm{Me}$ and $6-\mathrm{Cl} 3-\mathrm{Me}$ phenols

\begin{tabular}{|c|c|c|c|c|c|c|c|}
\hline \multirow{2}{*}{$\begin{array}{c}\text { Mode } \\
\text { (Wilson's) }\end{array}$} & \multicolumn{4}{|c|}{ 4-Cl 2-Mo Phenol 4-Cl 3-Me phenol } & \multicolumn{2}{|c|}{ 6-Cl3-Me phenol } & \multirow{2}{*}{ Assignments } \\
\hline & $\begin{array}{l}\text { freqnency } \\
\text { in } \mathrm{cm}^{-1}\end{array}$ & Int. & $\begin{array}{l}\text { frequency } \\
\text { in } \mathrm{cm}^{-1}\end{array}$ & Int. & $\begin{array}{l}\text { frequency } \\
\text { in } \mathrm{cm}^{-1}\end{array}$ & Int. & \\
\hline & 3610 & $\mathbf{s}$ & 3610 & $\mathbf{s}$ & 3560 & vs & $v(\mathrm{O}-\mathrm{H})$ stretching \\
\hline $20 a$ & 3100 & vw & 3090 & $\mathrm{vw}$ & 3080 & vw & $r(C-F)$ stretching \\
\hline 2 & 3060 & $\mathrm{vw}$ & 3060 & vw & .. & & $v($ C-H) stretching \\
\hline \multirow[t]{3}{*}{$20 b$} & 3030 & vw & 3030 & vw & 3040 & vw & $v(\mathrm{C}-\mathrm{H})$ stretching \\
\hline & 2960 & vw & 2960 & vw & 2960 & $w$ & $v_{\text {a }}$ in $\mathrm{CH}_{8}$ group \\
\hline & 2860 & $\mathbf{w}$ & 2850 & vw & 2850 & vw & $v$, in $\mathrm{CH}_{\mathrm{g}}$ group \\
\hline $8 b$ & 1610 & $\mathbf{s}$ & 1605 & w & 1605 & $\mathbf{w}$ & $v(C-C)$ stretching \\
\hline $8 a$ & 1580 & $\mathbf{w}$ & 1575 & vs & 1585 & vs & $v(\mathrm{C}-\mathrm{C})$ stretching \\
\hline \multirow[t]{2}{*}{$19 a$} & 1485 & vs & 1472 & $w$ & 1480 & s & $v(C-C)$ stretching \\
\hline & 1440 & vs & 1445 & vw & 1440 & $\mathbf{s}$ & $\delta_{\text {as }}$ in $\mathrm{CH}_{\text {a }}$ group \\
\hline \multirow[t]{3}{*}{$19 b$} & 1400 & vs & 1410 & s & 1410 & $w$ & $v(C-C)$ stretching \\
\hline & 1375 & s & 1370 & s & 1370 & s & $\delta+$ in $\mathrm{CH}_{2}$ group \\
\hline & 1345 & $\mathbf{w}$ & 1340 & $\mathbf{w}$ & 1340 & $\mathbf{w}$ & $\delta_{\mathrm{ss}}^{-}$in $\mathrm{CH}$, group \\
\hline 14 & 1310 & $\mathbf{s}$ & .. & & 1305 & vs & $v(\mathrm{C}-\mathrm{C})$ stretching \\
\hline 3 & 1270 & sh & 1275 & vvs & 1285 & s & $P(C-H)$ i.P. bending \\
\hline $7 a$ & 1250 & ve & 1235 & vs & 1250 & vs & $v(\mathrm{C}-\mathrm{OH})$ stretching \\
\hline \multirow[t]{2}{*}{13} & 1195 & vys & .. & & 1190 & vvs & $v\left(\mathrm{C}-\mathrm{CH}_{4}\right)$ stretching \\
\hline & 1150 & vvs & 1150 & vws & 1150 & vis & $\beta(\mathrm{OH})$ i.P. bending \\
\hline 15 & 1100 & vos & 1120 & $\mathbf{s}$ & 1125 & $\mathbf{s}$ & $B(C-H)$ i.P. bending \\
\hline $18 b$ & 1080 & sh & 1075 & $\mathbf{w}$ & 1085 & vw & $A(C-H)$ i.P. bending \\
\hline \multirow[t]{3}{*}{1} & 1035 & s & 1045 & vs & 1040 & $\mathbf{s}$ & Ring breathing \\
\hline & 1025 & s & 1025 & $\mathbf{s}$ & & & Rocking in $\mathrm{CH}_{4}$ \\
\hline & 985 & $\mathbf{s}$ & 995 & $\mathbf{s}$ & 995 & $\mathbf{s}$ & $\delta-$ in $\mathrm{CH}_{4}$ \\
\hline $17 b$ & 935 & vw & 935 & $\mathbf{s}$ & 935 & s & $y(\mathrm{C}-\mathrm{H})$ O.P. bending \\
\hline 5 & 865 & vs & 855 & $\mathbf{s}$ & 855 & s & $\gamma(\mathrm{C}-\mathrm{H})$ O.P. bending \\
\hline 11 & 800 & $\mathbf{s}$ & 805 & s & 795 & vvs & $y(C-H)$ O.P. bending \\
\hline 12 & 755 & vs & 765 & $w$ & 750 & s & $\phi(C-C-C)$ i.P. bending \\
\hline 4 & 715 & nw & 720 & s & 720 & sh & $\delta(C-C-C) O . P$, bending \\
\hline $6 b$ & 700 & w & 690 & $\mathrm{~s}$ & 695 & vw & $\begin{array}{l}\phi(C-C-C) \\
\text { i.P. bending }\end{array}$ \\
\hline \multirow[t]{2}{*}{$7 b$} & 650 & vs & 630 & vs & 630 & vs & $r(\mathrm{C}-\mathrm{CI})$ stretching \\
\hline & 610 & $\mathbf{w}$ & 610 & $\mathbf{w}$ & 610 & vw & $\gamma(\mathrm{OH})$ O.P. bending \\
\hline $16 a$ & 580 & w & 570 & $\mathbf{w}$ & 580 & $\mathbf{w}$ & $\delta(\mathrm{C}-\mathrm{C}-\mathrm{C}) \mathrm{O} . \mathrm{P}$ \\
\hline $6 a$ & 550 & $\mathbf{s}$ & 550 & $\mathbf{w}$ & 545 & $\mathbf{w}$ & $\phi(C-C-C)$ i.P. berding \\
\hline $16 b$ & 440 & w & 440 & vw & 445 & vvw & $\begin{array}{l}\delta(C-C-C) O . P . \\
\text { bending }\end{array}$ \\
\hline $9 b$ & 385 & $\mathbf{w}$ & 385 & s & 390 & vw & $\mathrm{A}\left(\mathrm{C}-\mathrm{CH}_{2}\right)$ i.P. bending \\
\hline $10 a$ & 355 & $\mathbf{w}$ & 355 & $\mathbf{w}$ & 350 & vvw & $\gamma(\mathrm{C}-\mathrm{OH})$ O.P. bending \\
\hline $9 a$ & 310 & $\mathbf{w}$ & 310 & $\mathbf{w}$ & 305 & vw & $A(C-C l)$ i.P. bending \\
\hline $10 b$ & 260 & $\mathbf{w}$ & 260 & $\mathbf{w}$ & 265 & $w$ & $\begin{array}{l}\gamma\left(\mathrm{C}-\mathrm{CH}, \mathrm{H}_{8}\right) \text { O.P. } \\
\text { bending }\end{array}$ \\
\hline $\begin{array}{l}15 \\
17 a\end{array}$ & 250 & $\mathbf{w}$ & 250 & $\mathbf{w}$ & $\ddot{0}$ & & $\gamma(\mathrm{C}-\mathrm{OH})$ O.P. bending \\
\hline $17 a$ & $\cdot \cdot$ & & .. & & 230 & $\mathbf{w}$ & $\gamma(\mathrm{C}-\mathrm{Cl})$ O.P. bending \\
\hline
\end{tabular}


frequencies as given in table 1 are based on the assignments made by earlier workers and the frequency ranges suggested by Varsanyi (1969).

3.1d. In-plane bending $\beta(C-H)$ and $\beta(C-X)$ vibrations. In general for trisubstitution $\mathrm{C}-\mathrm{H}$ in-plane bending vibrations appear in the frequency range $1070-1300 \mathrm{~cm}^{-1}$ (Varsanyi 1969). Earlier work on chlorinated methyl anilines has ascribed, $\mathrm{C}-\mathrm{Cl}$ in-plane bending mode to a frequency observed at $300 \mathrm{~cm}^{-1}$ while $\mathrm{C}-\mathrm{CH}_{3}$ in-plane bending has been assigned at $380 \mathrm{~cm}^{-1}$. The $\mathrm{C}-\mathrm{OH}$ in-plane bending vibration has been assigned at $245 \mathrm{~cm}^{-1}$ in phenol. Our assignments given in table 1 are in general agreement with the above.

3.1e. Out-of-plane bending $\delta(C-C-C)$ vibrations. There are three $(\mathrm{C}-\mathrm{C}-\mathrm{C})$ outof-plane bending vibrations in substituted benzenes. In general for trisubstitution these vibrations appear in the froquency range $420-700 \mathrm{~cm}^{-1}$ (Varsanyi 1969). We have also observed these frequencies in the suggested range.

3.1f. Out-of-plane bending $\gamma(C-H)$ and $\gamma(C-X)$ vibrations. According to Randle and Whiffen (1955) the $\mathbf{C}-\mathbf{H}$ out-of-plane deformations generally appear in the range $750-1000 \mathrm{~cm}^{-1}$ in the infrared spectra of substituted benzenes. $C-X$ outof-plane bending vibrations are generally observed at very low frequencies. Their assignments are also included in table 1 .

The internal vibrations of $\mathrm{CH}_{3}$ and $\mathrm{OH}$ groups have also been assigned in analogy with earlier assignments.

\subsection{Ultraviolet absorption spectrum}

The electronic absorption bands of 4- $\mathrm{Cl} 2-\mathrm{Me}, 4-\mathrm{Cl} 3-\mathrm{Me}$ and $6-\mathrm{Cl} 3-\mathrm{Me}$ phenol lie in the region $290-260 \mathrm{~nm}$. The transition is the analog of $260 \mathrm{~nm}$ transition in benzene, but it is expected to show the features of an allowed transition because of the reduced symmetry of the present compounds. These features include a strong $(0,0)$ band on the longer wavelength side of the electronic transition, and appearance of prominent bands involving totally symmetric vibrations. The ultraviolet absorption spectrum of $4-\mathrm{Cl} 2-\mathrm{Me}, 4-\mathrm{Cl} 3-\mathrm{Me}$ and $6-\mathrm{Cl} 3-\mathrm{Me}$ phenols is shown in figures $2 a, 2 b$ and $2 c$.

On the longer wavelength side of the absorption spectrum, a very strong band has been observed at 34890,34934 and $35595 \mathrm{~cm}^{-1}$ for $4-\mathrm{Cl} 2-\mathrm{Me}, 4-\mathrm{Cl} 3-\mathrm{Me}$ and 6-Cl 3-Me phenols respectively. These aro the strongest bands of the respective absorption spectrum and appear with very good intesity even at the lowest pressure of the absorbing vapour. They have been taken as the $(0,0)$ bands for the three different compounds.

Three hot bands involving three low lying ground state vibrations have been observed in the spectrum of 4-Cl 2-Me and 6-Cl 3-Me phenol. These vibrations have the magnitudes 150,315 and $441 \mathrm{~cm}^{-1}$ and 139,232 and $305 \mathrm{~cm}^{-1}$ respectively in tho two compounds. Four hot bands have been observed in the spectrum of 4-Cl 3-Mo phenol involving ground state vibrations of magnitude 181, 273, 350 and $436 \mathrm{~cm}^{-1}$. In addition to these ground state vibrations soveral excited state 
fundamental frequencies have been observed with magnitude $254,399,463,590$, $634,741,979,1080,1135,1222$ and $1351 \mathrm{~cm}^{-1}$ in 4-Cl 2-Me phenol, 263, 336, $420,621,712,929,1130,1235$ and $1367 \mathrm{~cm}^{-1}$ in $4-\mathrm{Cl} \mathrm{3-Me} \mathrm{phenol} \mathrm{and} \mathrm{466,} \mathrm{552,}$ $626,696,973,1052,1189,1234$ and $1382 \mathrm{~cm}^{-1}$ in $6-\mathrm{Cl} 3-\mathrm{Me}$ phenol. The ultraviolet bands and their assignment in terms of the above frequencies are given in table 2.

The excited state fundamentals have been tentatively correlated with the ground state frequencies as shown in table 3.

Table 2. Ultraviolet absorption of $4 \mathrm{Cl} 2-\mathrm{Mo}$ phenol.

\begin{tabular}{|c|c|c|c|}
\hline $\begin{array}{l}\text { Position of } \\
\text { bands }\left(\mathrm{cm}^{-1}\right)\end{array}$ & $\begin{array}{l}\text { Rel. } \\
\text { Int. }\end{array}$ & $\begin{array}{l}\text { Separation from } \\
(0,0) \text { band }\end{array}$ & Assignments \\
\hline 34449 & $v w$ & $0-441$ & $0-441$ \\
\hline 34575 & vw & $0-315$ & $0-315$ \\
\hline 34740 & $\mathbf{w}$ & $0-\quad 150$ & $0-150$ \\
\hline 34821 & $\mathrm{~ms}$ & $0-\quad 69$ & $0-\quad 69$ \\
\hline 34890 & vs & $(0,0)$ & $(0,0)$ \\
\hline 34965 & ms & $0+\quad 75$ & $0+75$ \\
\hline 34995 & ms & $0+105$ & $0+105$ \\
\hline 35144 & $\mathbf{w}$ & $0+254$ & $0+254$ \\
\hline 35289 & $\mathrm{~ms}$ & $0+399$ & $0+399$ \\
\hline 35353 & $w$ & $0+463$ & $0+463$ \\
\hline 35480 & ms & $0+590$ & $0+590$ \\
\hline 35524 & ms & $0+634$ & $0+634$ \\
\hline 35631 & $\mathbf{s}$ & $0+741$ & $0+741$ \\
\hline 35685 & $\mathbf{w}$ & $0+795$ & $0+2 \times 399$ \\
\hline 35760 & $\mathbf{w}$ & $0+870$ & $0+2 \times 399+75$ \\
\hline 35869 & s & $0+979$ & $0+979$ \\
\hline 35968 & ms & $0+1080$ & $0+1080$ \\
\hline 36025 & $\mathbf{w}$ & $0+1135$ & $0+1135$ or $741+399$ \\
\hline 36112 & $\mathbf{w}$ & $0+1222$ & $0+1222$ \\
\hline 36241 & $\mathbf{s}$ & $0+1351$ & $0+1351$ \\
\hline 36308 & ms & $0+1418$ & $0+1351+75$ \\
\hline 36409 & $\mathbf{w}$ & $0+1519$ & $0+1351+75+105$ \\
\hline 36545 & $\mathbf{w}$ & $0+1655$ & $0+1080+590$ \\
\hline 36669 & $\mathbf{w}$ & $0+1777$ & $0+1135+634$ \\
\hline 36803 & vw & $0+1913$ & $0+1351+634-69$ \\
\hline 36853 & $\mathbf{v w}$ & $0+1963$ & $0+2 \times 979$ \\
\hline 36974 & vw & $0+2084$ & $0+1351+741$ \\
\hline 37233 & vw & $0+2343$ & $0+1351+979$ \\
\hline 37333 & vw & $0+2443$ & $0+1351+1080$ \\
\hline
\end{tabular}


Table 2. (Contd.)

\begin{tabular}{llll}
$\begin{array}{l}\text { Position of } \\
\text { bands } \mathrm{cm}^{-1}\end{array}$ & $\begin{array}{l}\text { Rel. } \\
\text { Int. }\end{array}$ & $\begin{array}{c}\text { Separation from } \\
(0,0) \text { band }\end{array}$ & Assignments \\
\hline
\end{tabular}

UV absorption of 4-Cl3-Me phenol

$\begin{array}{llll}34498 & \text { ww } & 0-436 & 0-436 \\ 34584 & \text { w } & 0-350 & 0-350 \\ 34661 & \text { w } & 0-273 & 0-273 \text { or } 0-181-94 \\ 34753 & \text { s } & 0-181 & 0-181 \\ 34840 & \text { s } & 0-94 & 0-94 \\ 34934 & \text { vs } & (0,0) & \mathbf{0 , 0 )} \\ 35022 & \text { s } & 0+88 & 0+88 \\ 35109 & \text { w } & 0+175 & 0+2 \times 88 \\ 35197 & \text { w } & 0+263 & 0+263 \\ 35270 & \text { ms } & 0+336 & 0+336 \\ 35354 & \text { s } & 0+420 & 0+420 \\ 35555 & \text { s } & 0+621 & 0+621 \\ 35646 & \text { s } & 0+712 & 0+712 \\ 35863 & \text { ms } & 0+929 & 0+929 \\ 36064 & \text { s } & 0+1130 & 0+1130 \\ 36169 & \text { s } & 0+1235 & 0+1235, \text { or } 0+2 \times 621 \\ 36301 & \text { s } & 0+1367 & 0+1367 \\ 36483 & \text { w } & 0+1549 & 0+929+621 \\ 36588 & \text { w } & 0+1654 & 0+929+712 \\ 36685 & \text { w } & 0+1751 & 0+712+621+420 \\ 36798 & \text { w } & 0+1864 & 0+2 \times 929 \\ 36898 & \text { ms } & 0+1964 & 0+299+621+470 \\ 36996 & \text { ms } & 0+2062 & 0+1367+712 \\ 37226 & \text { ms } & 0+2292 & 0+1367+929 \\ 37343 & \text { ms } & 0+2409 & 0+1367+1130-94 \text { or } \\ & & & 1367+621+420 \\ 37583 & \text { w } & 0+2649 & 2+1367-94 \\ 37659 & \text { w } & 0+2725 & 0+2 \times 1367 \\ 37951 & \text { w } & 0+3017 & 0+1367+929+712 \\ 38148 & \text { w } & 0+3211 & 0+1367+2 \times 929 \\ 38362 & \text { vw } & 0+3433 & 0+2+1367+712 \\ & & & \end{array}$

UV absorption of 6-Cl 3-Mo phenol

$\begin{array}{llll}35289 & \text { vw } & 0-305 & 0-305 \\ 36363 & \text { w } & 0-232 & 0-232 \\ 35456 & \text { B } & 0-139 & 0-139 \\ 35517 & \text { vs } & 0-77 & 0-77 \\ 35594 & \text { ww } & (0,0) & (0,0) \\ 35677 & \text { w } & 0+82 & 0+82 \\ 36062 & \text { vw } & 0+466 & 0+466 \\ 36147 & \text { B } & 0+552 & 0+552 \\ 36221 & \text { vs } & 0+626 & 0+626 \\ 36291 & \text { vs } & 0+696 & 0+696 \\ 36369 & \text { vww } & 0+774 & 0+696+82 \\ 36462 & \text { vww } & 0+867 & 0+696+2 \times 82 \\ 36568 & \text { s } & 0+973 & 0+973\end{array}$


Table 2. (Contd.)

\begin{tabular}{llll}
\hline $\begin{array}{l}\text { Position of } \\
\text { bands } \mathrm{cm}^{-1}\end{array}$ & $\begin{array}{l}\text { Rol. } \\
\text { Int. }\end{array}$ & $\begin{array}{c}\text { Separation from } \\
(0,0) \text { band }\end{array}$ & \multicolumn{1}{c}{ Assignments } \\
\hline 36646 & s & $0+1052$ & $0+1052$ \\
36784 & w & $0+1189$ & $0+1189$ \\
36828 & ms & $0+1234$ & $0+1234$ \\
36919 & ms & $0+1325$ & $0+699+626$ \\
36977 & ms & $0+1382$ & $0+1382$ or $2 \times 696$ \\
37029 & w & $0+1435$ & $0+973+466$ \\
37244 & w & $0+1650$ & $0+1189+466$ \\
37302 & w & $0+1708$ & $0+1234+466$ \\
37339 & w & $0+1744$ & $0+1052+696$ \\
37463 & vw & $0+1868$ & $0+2 \times 973-77$ \\
37553 & vw & $0+1959$ & $0+2 \times 973$ \\
37655 & vw & $0+2060$ & $0+2 \times 973+466-77$ or \\
37918 & vvw & $0+2323$ & $0+2 \times 1382+973$ \\
& & & $0+2 \times 973+466$ \\
38000 & vww & $0+2406$ & $0+2 \times 1052+626$ \\
38317 & vvw & $0+2722$ & \\
& & &
\end{tabular}

$\mathrm{s}=$ strong, $v s=$ very strong, vvs $=$ very very strong, $\mathrm{ms}=$ medium strong, $w=$ weak, $\mathrm{vw}=$ very weak, $\mathrm{ww}=$ very very weak.

Table 3. Correlation of frequencies in infrarod and ultraviolet spectra.

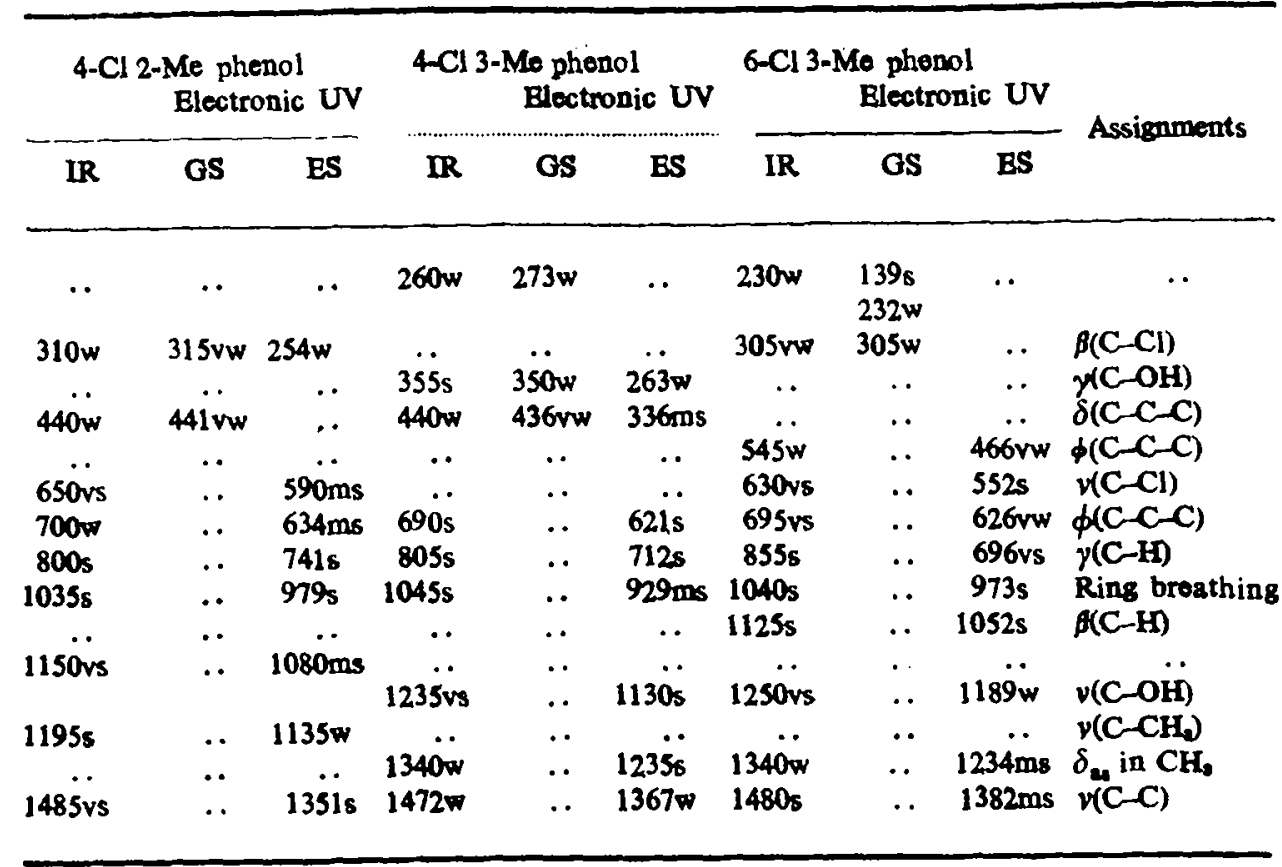

GS, ground state; ES, oxcited state. 


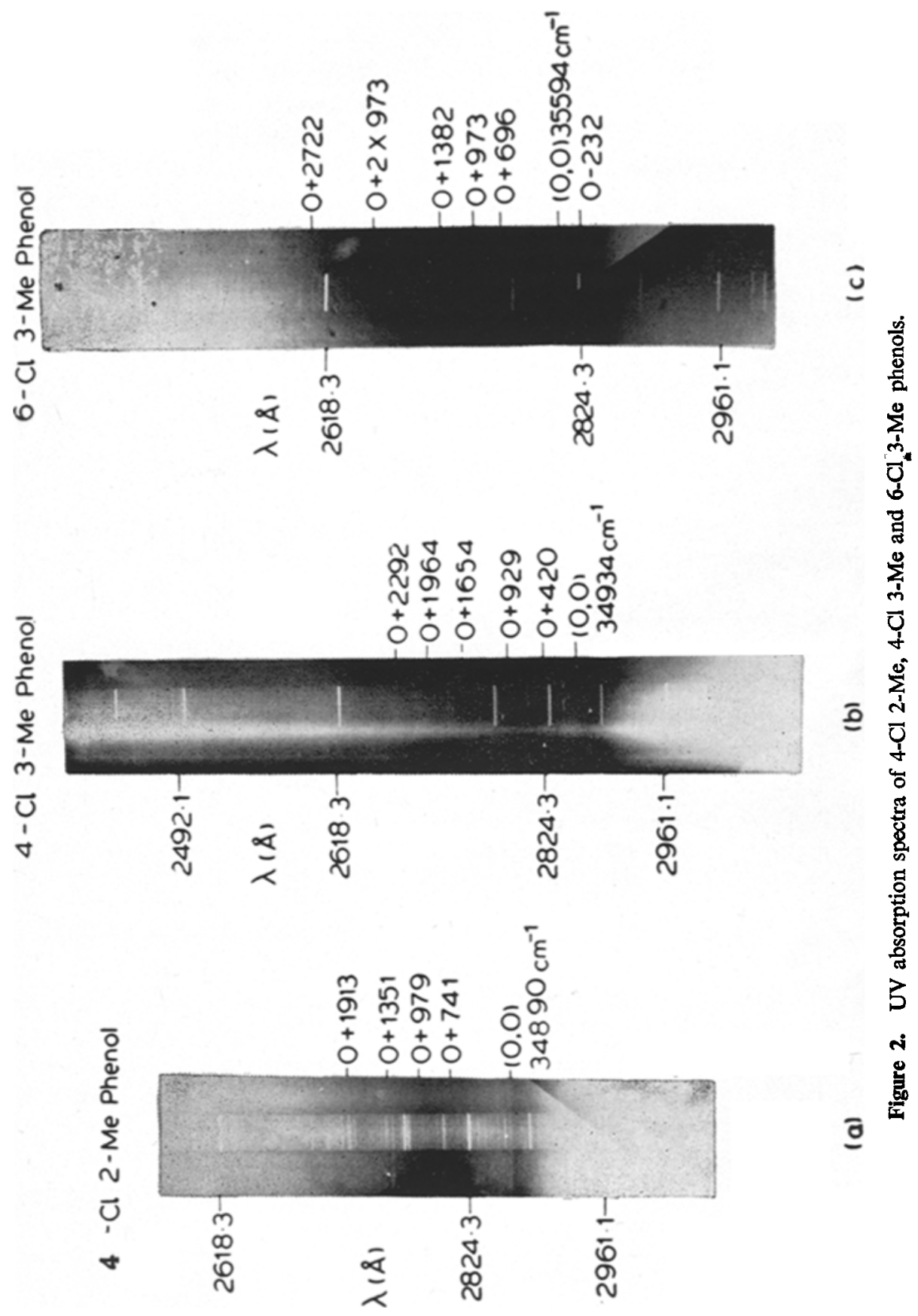


The ring breathing vibration in the excited state has the magnitude $979 \mathrm{~cm}^{-1}$ in 4-Cl $2-\mathrm{Me}, 929 \mathrm{~cm}^{-1}$ in 4-Cl 3-Me and $973 \mathrm{~cm}^{-1}$ in $6-\mathrm{Cl} 3-\mathrm{Me}$ phenol and is characterised by the observation of bands involving second quanta of this vibration. It also appears in combination with other prominent vibrations.

Another prominent excited state vibration is observed at $1357 \mathrm{~cm}^{-1}$ for $4-\mathrm{Cl}$ 2-Me, at $1367 \mathrm{~cm}^{-1}$ for 4-Cl 3-Me and at $1382 \mathrm{~cm}^{-1}$ for $6-\mathrm{Cl} 3-\mathrm{Me}$ phenol. This is correlated with the respective ground state frequency observed in infrared spectrum at $1400 \mathrm{~cm}^{-1}, 1410 \mathrm{~cm}^{-1}$ and $1410 \mathrm{~cm}^{-1}$ and is assigned to a (C-C) stretching mode.

In addition to these fundamental vibrations difference bands involving the frequencies $-69,75$ and $105 \mathrm{~cm}^{-1}$ for $4-\mathrm{Cl} 2-\mathrm{Me},-94$ and $88 \mathrm{~cm}^{-1}$ for $4-\mathrm{Cl} 3-\mathrm{Me}$ and -77 and $82 \mathrm{~cm}^{-1}$ for 6-Cl 3-Me phenols have also been observed. It is not possible at this stage to correlate these difference frequencies to specific fundamentals.

\section{Acknowledgements}

The authors are thankful to Drs K N Upadhya, S N Thakur and S B Rai for their help and cooperation during the work. One of us (RBS) is thankful to the University Grants Commission, New Delhi, for financial assistance.

\section{References}

Ballamy L J 1964 Infrared spectra of complex molecules (London : Methuen and Co.)

Bellamy L J and Davis M J 1948 Chem. Phys. 34267

Cave W T and Thompson H W 1950 Disc. Farad. Soc. 9350

Green J H S 1962 Spectrochim. Acta 1839

Groen J H S and Harrison D J 1971 Spectrochim. Acta A27 793

Mecke $R$ and Rassmy Z 1955 Electrochem. 59866

Randle R R and Whiffen D H 1955 Proceedings of Symposium on Molecular Spectra, Institute of Petroleum, London

Rao C N R 1963 Chemical applications of infrared spectroscopy (New York: Academic Press) p. 309

Rao P Rama Koteswara 1962 Proc. Indian Acad. Sci. A55 232

Sanyal N K and Pandey A N 1973 Indian J. Pure Appl. Phys. 11913

Sharma S N and Dwivedi C P D 1976 Indian J. Phys. 5025

Varsanyi G 1969 Vibrational spectra of benzene derivatives (New York: Academic Press)

\section{Footnotes}

$8=$ strong, $\mathrm{vs}=$ very strong, vvs $=$ very very strong, $w=$ weak, $v w=$ very weak, $v v w=$ very very weak.

$\boldsymbol{y}=$ Stretching.

$\beta \quad$ in-plano bending.

$\gamma=$ Out of-plane bending.

$v_{1}=$ Symmotric stretching vibration of the groups.

$v_{w}=$ Asymmetric stretching vibration of the groups.

$\delta_{\mathrm{g}}=$ Symmetric bending vibration of $\mathrm{CH}_{\mathrm{a}}$ group.

$\delta_{i}^{+}=$Asymmetric bending vibration of $\mathrm{CH}_{\mathrm{a}}$ group.

$\delta_{\mathrm{a}}=$ Asymmetric bending vibration of $\mathrm{CH}_{\mathrm{s}}$ group.

$\phi \quad=$ in-plane bending of the ring.

$\delta \quad=$ Out-of-plane of the ring.

P. (A) -9 